\title{
Effects of Grain Angle on Reproducibility and Accurate Measurement of Moisture Content of Wood Samples Using a Pin-Style Moisture Meter
}

\author{
Reynolds Okai \\ College of Technology Education, University of Education, Winneba, P.O. Box 1277, Kumasi, Ghana
}

\begin{abstract}
Studies were conducted on the effects of grain angle on reproducibility and accurate measurement of moisture content of four wood samples using a pin-style moisture meter. The wood samples were partitioned into four quadrants and moisture contents were measured along the grain direction in the first and second quadrants from 0 degree to 150 degrees insteps of 30 degrees. Experimental results indicated that the average moisture content remained constant as the grain angle increased. Repeated measurements of moisture content at different grain angles or points on the wood surface showed similar patterns of variation. Within-point standard deviations of the moisture contents were greater than between-point standard deviations. A non-destructive method of measuring moisture content at the same location or point on the wood surfaces could not be proposed because of the high variation of moisture content when repeated measurements were taken at the same point. Instead, accurate measurements of moisture content could be obtained at random positions within a radius of $30 \mathrm{~mm}$ from the point of intersection of the moisture content axis and the grain angle.
\end{abstract}

Key words: Moisture content, moisture meter, reproducibility, within-point standard deviation, between-point standard deviation.

\section{Introduction}

The essence of drying lumber in the timber industry is to remove the moisture in the wood to a preferred level to stabilise its operating conditions. If lumber is not properly dried, it will lead to loss in strength, susceptibility of the lumber to decay and insects attack and more importantly deformation by warping.

The moisture content of a wood sample is defined as the ratio of the mass of water in a sample to the mass of solids in the sample, expressed as a percentage. Moisture content distributions in branchwood and stemwood of Aningeria robusta and Terminalia ivorensis were investigated by Okai, R. et al. $[1,2]$ in order to determine the suitability of branchwood as raw material for the downstream processing sector. The effects of moisture content on

Corresponding author: Reynolds Okai, Ph.D., main research fields: forest engineering, mechanical engineering, forest products science and technology. the strength properties of branchwood have also been reported by Okai, R. et al. [3]. Moisture content distributions and their effects on strength properties of branchwood, stemwood and rootwood of iroko and emire trees have been reported by Amoah, M. et al. [4]. If moisture content is not properly controlled during wood processing, it could affect the running stability or vibration of the bandsaw machine [5-14].

There are basically three main methods of moisture content determination. These are oven dry method, which is a destructive type of moisture content determination and gives a definite value of the moisture content; the pin-style moisture meter, which is a non-destructive type of moisture content determination. The third method is the pinless meter which uses electromagnetic wave technology to measure the moisture content.

In the timber industry, non-destructive method of measuring the moisture content of wood samples at different locations is preferred. This is done by using 


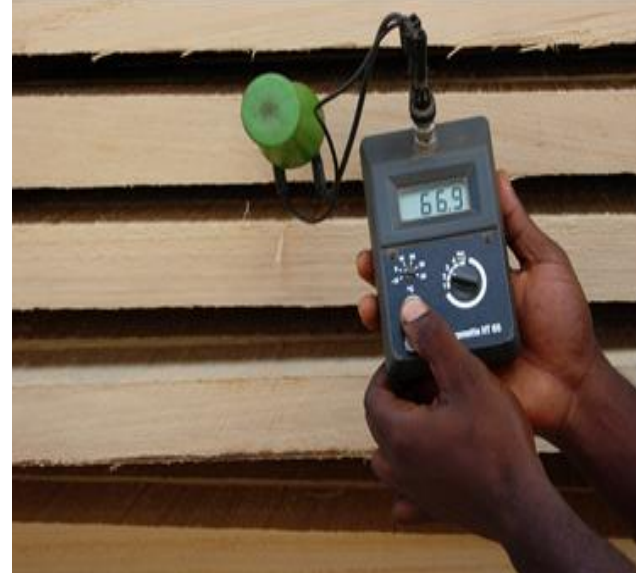

Fig. 1 Measuring moisture content of air dried lumber using pin-style moisture meter.

the pin-style moisture meter which allows for several readings to be taken within a relatively short time. The same cannot be said for the oven dry method, which is much slower and labour intensive. Fig. 1 shows a photo of pin-style moisture meter used to measure the moisture content of air dried lumber at a recorded moisture content of $66.9 \%$.

It is expected that because of the variation of moisture in wood, in both the radial and tangential directions, the moisture meter may not record the same readings at different locations on the wood surface. Besides, it is not known if the moisture meter will exhibit reproducibility, which refers to the consistency of the moisture meter to show repeatedly similar patterns of variations at different grain angles or grain directions.

The purpose of this study is to determine the effects of grain angle on reproducibility and accurate measurement of moisture content of wood samples.

\section{Theoretical Considerations}

\subsection{Pin-Style and Pinless Moisture Meters}

In the wood industry, two technologies namely pin-style meters and pinless meters are used to measure the moisture content of wood. Pin-style meters use electrical resistance to record the moisture content readings in wood. After the two probes or pins, are inserted into the wood, a small electrical current is passed between the points, and the amount of resistance is correlated into a moisture content reading. Because moisture is a good electrical conductor, the wetter the wood, the less resistance there would be to the current and vice versa. Because of the type of technology used, pin meter accuracy is affected by variances in the naturally-occurring chemical composition of wood species, but not as impacted by density variability from one piece of wood to the other.

Pinless meters, also referred to as non-damaging or non-destructive meters because they do not have to penetrate the wood use electromagnetic wave technology to measure the moisture content. The meters send out electrical waves at a certain electromagnetic frequency that creates an electromagnetic field in the area under the sensor pad. The meters then produce moisture content correlating to the signal it reads back. Pinless meters typically test a much larger area than pin-style meters and can scan the wood for a more complete moisture content picture. However, this technology also has its own limitations and can be impacted by density variations.

\subsection{Analysis of Moisture Content Measurement in Wood Samples}

The standard deviation of a set of measurement is a useful parameter in precision engineering when accuracy and reproducibility are brought into play. In wood processing, standard deviation of a board thickness is a useful parameter to determine lumber thickness variation [11]. The standard deviation of repeated readings of moisture content at the same points on the surface of lumber using pin-style moisture meter can be used to calculate thewithin-point standard deviation, $S_{w}$, which is the average of the standard deviations of moisture contents repeatedly measured at individual points. The between-point standard deviation, $S_{b}$, is the standard deviation of the average moisture contents repeatedly measured at individual points. Eqs. (1-3) can be used to determine the standard deviation $-S_{j}$, of repeated measured moisture 
contents at a point on the wood surface, within-point standard deviation- $S_{w}$ and between-point standard deviation $-S_{b}$, respectively [11].

$$
\begin{gathered}
s_{j}=\sqrt{\frac{\sum_{j=0}^{N_{j}} x_{j}^{2}-\left(\frac{1}{N_{j}}\left(\sum_{j=0}^{N_{j}} x_{j}\right)^{2}\right)}{N_{j}-1}} \\
S_{w}=\sqrt{\frac{\sum_{j=0}^{k} S_{j}^{2}}{k}} \\
s_{b}=\sqrt{\frac{\sum_{j=0}^{k} A_{j}^{2}-\left(\frac{1}{k}\left(\sum_{j=1}^{k} A_{J}\right)^{2}\right)}{k-1}}
\end{gathered}
$$

The variables used in describing Eqs. (1-3) above are defined as:

$A_{j}$ : average moisture content at point $j$;

$K$ : number of points;

$N_{j}$ : number of measurements at point $j$;

$S_{j}$ : standard deviation for moisture contents at point $j$; $X_{j}$ : measurement from individual points.

\section{Materials and Methods}

\subsection{Extraction of Wood Samples from the Forest}

Four wood species: Elais guineensis, Milicia excelsa, Khaya ivorensis and Triplochiton scleroxylon of tropical origin were selected for the study. Wood samples from Elais guineensis were extracted from the Pra-Anum Forest Reserve in the moist semi-deciduous forest zone, whilst the rest of the species were extracted from the Bobiri Forest Reserve at Kubease also in the moist semi-deciduous forest zone. The wood species were sawn into beams and transported to the wood laboratory of the Department of Construction and Wood Technology of the University of Education, Winneba.

\subsection{Preparation of Wood Samples and Measurement of Moisture Content}

Three wood samples from the butt portion of each of the four species were sawn to the following dimensions: width $-90 \mathrm{~mm}$, breadth $-90 \mathrm{~mm}$ and thickness $-50 \mathrm{~mm}$. The samples were then partitioned into four quadrants and measurements of moisture contents taken in the first and second quadrants as shown in Fig. 2. The grain angle or grain directions were marked on the surface of each sample from 0 degree to 150 degrees in steps of 30 degrees. Measurements of moisture contents using pin-style moisture meter (Model GANN Hydromette HT85T) were in the order of $0,30,60,90,120$ and 150 degrees also shown in Fig. 2.

Measurements of moisture contents in the direction of the grain orientation corresponded to 0 degree, whilst measurement perpendicular to the grain orientation corresponded to 90 degrees. The two probes or pins of the moisture meter, which were 30 $\mathrm{mm}$ apart, were positioned along the grain directions at $30 \mathrm{~mm}$ from the point of intersection of the horizontal and vertical axis of the first and second quadrants at six points. These points are: $\mathrm{AB}, \mathrm{CD}, \mathrm{EF}$, $\mathrm{GH}, \mathrm{IJ}$ and $\mathrm{KL}$, corresponding to grain angles of 0,30 , $60,90,120$ and 150 degrees respectively.

A photo of the pin-style moisture meter used to measure the moisture content at different grain angles is shown in Fig. 3.

Measurement of the moisture content at each point was repeated fifty times. The moisture contents recorded from each point on the wood samples were analysed statistically using Eqs. (1-3). Within-point standard deviation and between-point standard deviation of moisture content were computed to determine if there was reproducibility in the readings recorded at each point. The standard deviation of moisture content at each point was determined. Thereafter, within-point standard deviation was determined by computing the average standard deviation of the individual standard deviation of moisture content at each point using Eq. (2). The mean moisture content recorded at each point was also determined. Thereafter, between-point standard deviation was determined by computing the standard deviation of the mean moisture contents at the six points using Eq. (3). 


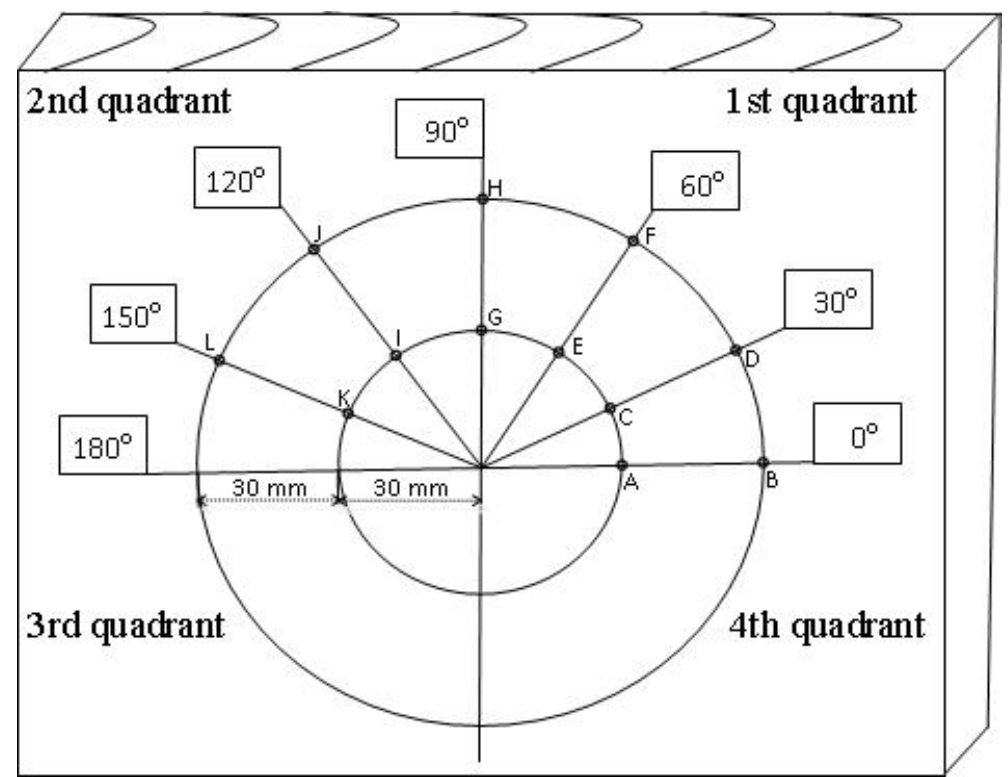

Fig. 2 Partitioning of the wood surface into four quadrants showing the grain angles and points AB, CD, EF, GH, IJ and KL where the moisture contents were measured.

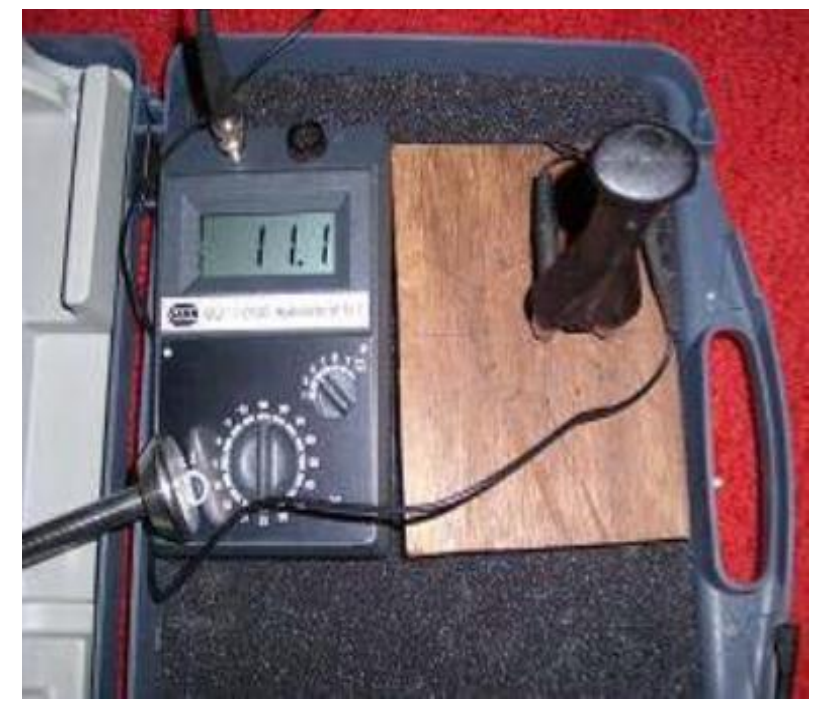

Fig. 3 Pin-style moisture meter used to measure the moisture content at different grain angles.

\section{Results and Discussion}

\subsection{Grain Angle and Moisture Content Distribution}

Wood is a heterogeneous material, and therefore moisture content distribution in the radial and tangential direction is not uniform. Studies have shown that cutting force is influenced by grain angle [3]. In this section, the relationship between grain angle and moisture content shall be discussed.

Fig. 4 shows the relationship between mean moisture content and grain angle of wood samples from Elais guineensis, Milicia excelsa, Khaya ivorensis and Triplochiton scleroxylon measured at six locations on the surface of the wood samples. It can be seen from Fig. 4 that no clear correlation could be established between moisture content and grain angle. As the grain angle increased, the moisture content remained almost constant.

If the moisture content in wood is not influenced by grain angle, then one can conclude that the variation of cutting force with grain angle needs to be studied in isolation without considering the moisture content. It is important to explain why it was concluded that a clear relationship could not be established between moisture content and grain angle. From Fig. 4, a linear equation was developed for the moisture content- $y$ as a function of the grain angle $-x$ for each of the four wood species and the results presented in Table 1.It can be seen from Table 1 that the gradient $-m$ of the straight line is almost zero for all the species. The intercept $-c$ on the moisture content axis has values of $\mathrm{c}=11.95 \%, 16.57 \%, 13.12 \%$ and $20.69 \%$ for Milicia excelsa, Triplochiton scleroxylon, Khaya ivorensis and Elais guineensis respectively. 


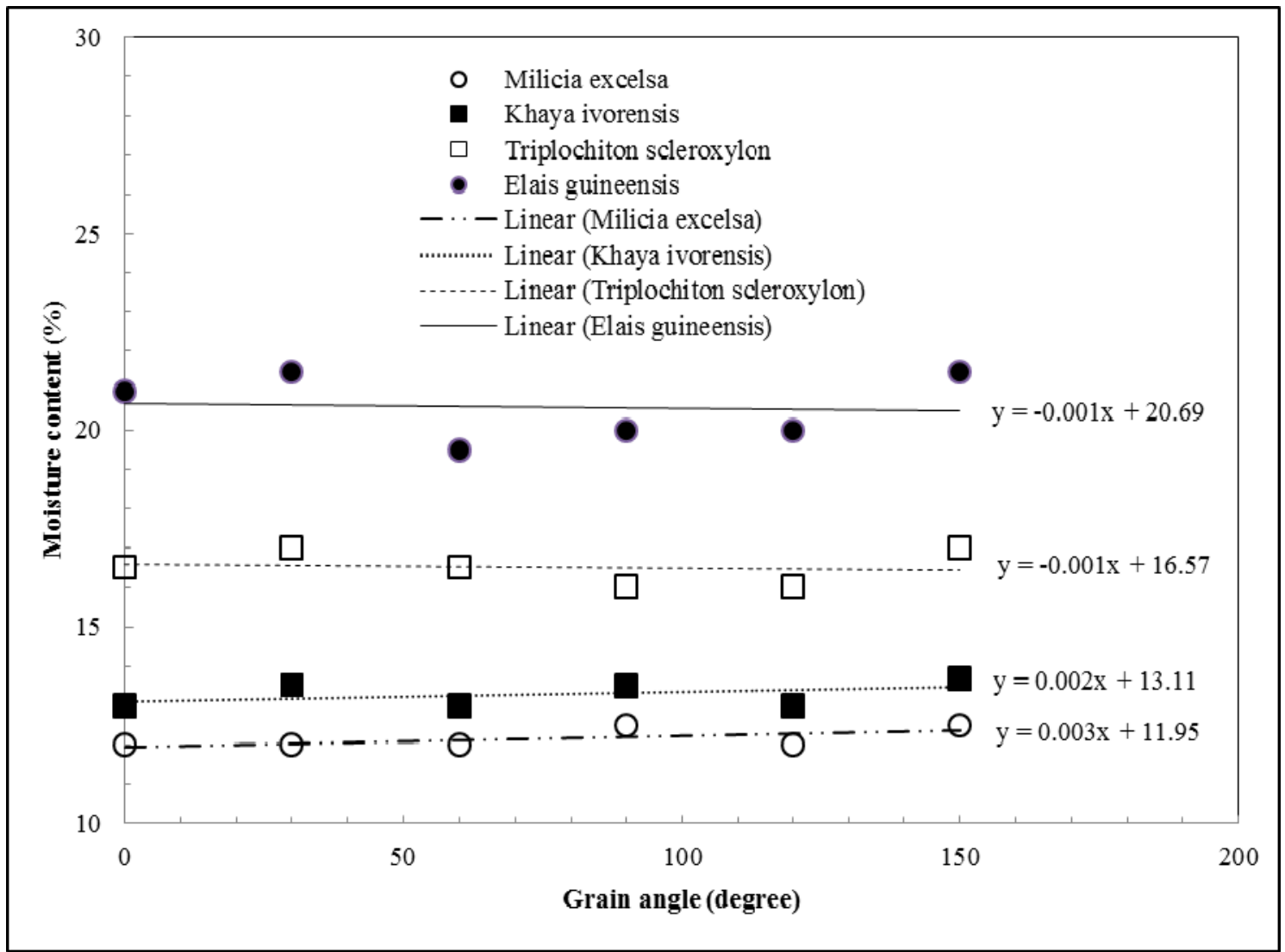

Fig. 4 Relationship between mean moisture content and grain angle of wood samples.

Table 1 A theoretical model for moisture content, $y$ and grain angle, $x$ for wood samples from Elais guineensis, Miliciaexcelsa, Khaya ivorensis and Triplochiton scleroxylon.

\begin{tabular}{llll}
\hline Species & Equation & $\mathrm{m}$ & $\mathrm{c}$ \\
\hline Milicia excelsa & $\mathrm{y}=0.003 \mathrm{x}+11.95$ & 0.003 & 11.95 \\
Khaya ivorensis & $\mathrm{y}=0.002 \mathrm{x}+13.11$ & 0.002 & 13.11 \\
Triplochiton scleroxylon & $\mathrm{y}=-0.001 \mathrm{x}+16.57$ & -0.001 & 16.57 \\
Elais guineensis & $\mathrm{y}=-0.001 \mathrm{x}+20.69$ & -0.001 & 20.69 \\
\hline
\end{tabular}

$* \mathrm{~m}$ is the gradient of the equation and $\mathrm{c}$ is the intercept on the moisture content axis.

\subsection{Within-Point and Between-Point Standard recorded higher within-point and between-point}

Deviation of Moisture Content

Table 2 shows within-point and between-point standard deviation of moisture content of the four wood samples selected for the study. It can be seen that regardless of the wood species, within-point standard deviation was always greater than between-point standard deviation. Thus, the ratio of within-point standard deviation to between-point standard deviation was greater than unity. A close observation of Table 2 shows that species with higher moisture content standard deviation. The high value of within-point standard deviation is due to the high variation of moisture content for repeated measurements. It can be concluded that variations in values between within-point, and between-point, standard deviations as regards moisture content were due to the structure or chemical composition of the wood and not any technical error attributable to the pin-style moisture meter.

An explanation for the higher values of within-point standard deviation of moisture content can be given as 
Table 2 Within-point standard deviation $-S_{w}$ and between-point standard deviation $-S_{b}$ from moisture content-MC of wood samples from Milicia excelsa, Khaya ivorensis, Triplochiton scleroxylon and Elais guineensis.

\begin{tabular}{lllll}
\hline Species & $\mathrm{MC}(\%)$ & $\mathrm{S}_{\mathrm{b}}$ & $\mathrm{S}_{\mathrm{w}}$ & $\mathrm{S}_{\mathrm{w}} / \mathrm{S}_{\mathrm{b}}$ \\
\hline Milicia excelsa & 12.17 & 0.29 & 0.87 & 3.00 \\
Khaya ivorensis & 13.28 & 0.32 & 0.94 & 2.94 \\
Triplochiton scleroxylon & 16.50 & 0.45 & 1.07 & 2.38 \\
Elais guineensis & 20.58 & 0.86 & 1.56 & 1.81 \\
\hline
\end{tabular}

follows: when repeated measurements were taken at the same point, the wood cells were broken or destroyed and the water in the cells was absorbed into the atmosphere thus accounting for variation of moisture content. The higher the moisture contents of the wood the higher the rate of release of water from the wood into the atmosphere.

\subsection{Reproducibility}

This section is solely devoted to reproducibility, which refers to the consistency of the moisture meter to show repeatedly, similar patterns of variation. Note that reproducibility forms the basis of this study and therefore attempts have been made to treat this topic in a holistic manner. As shown in Table 2, similar patterns of variation were recorded, that is, within-point standard deviations were always greater than between-point standard deviation for all the species selected for the study.

To address the issue of reproducibility of moisture content measurement, one needs to take a critical look at non-destructive method of moisture content measurement. Ordinarily, the best approach would be to measure the moisture content of wood samples at the same location for consistent readings due to the variation of moisture content along the radial or tangential directions of wood. Table 2 clearly suggests that there will be high variation of moisture content if measurements were taken at the same location or points as indicated by higher values of within-point standard deviation. However, consistent readings could be recorded if measurements of moisture content were taken at different locations or points on the wood surface as indicated by lower values of between-point standard deviation.

\section{Conclusions}

It has been established in this study that moisture content was not influenced by grain anglewithin a radius of $30 \mathrm{~mm}$. Repeated measurements of moisture content at different points or locations showed similar patterns of variation and this is referred to as reproducibility. A non-destructive method of measuring moisture content at the same location could not be proposed because of the high variation of moisture contents.

\section{References}

[1] Okai, R., Frimpong-Mensah, K., and Yeboah, D. 2003. "Characterization of Moisture Content and Specific Gravity of Branchwood and Stemwood of Aningeria robusta and Terminalia ivorensis." European Journal of Wood and Wood Products 61 (2): 155-158.

[2] Okai, R. 2001. Sawing Characteristics and Mechanical Strength Properties of Branchwood of Some Ghanaian Timber Species from Sustainably Managed Forests. Yokohama, Japan: International Tropical Timber Organization (ITTO).

[3] Okai, R., Frimpong-Mensah, K., and Yeboah, D. 2004. "Characterization of Strength Properties of Branchwood and Stemwood of Some Tropical Hardwood Species." Wood Science and Technology 38 (2): 163-171.

[4] Amoah, M., Appiah-Yeboah, J., and Okai, R. 2012. "Characterisation of Physical and Mechanical Properties of Branch, Stem and Root Wood of Iroko and Emire Tropical Trees." Research Journal of Applied Sciences, Engineering and Technology 4 (12): 1754-1760.

[5] Okai, R., Kimura, S., and Yokochi, H. 1997. "Dynamic Characteristics of the Bandsaw III, Effects of Workpiece Thickness and Its Position from the Ground on Self-Excited Vibration and Washboarding during Sawing." Journal of the Japan Wood Research Society 43 (7): 551-557.

[6] Okai, R., Tanaka, C., Iwasaki, Y., and Ohtani, T. 2005. "Application of a Novel Technique for Band Sawing Using a Tip-Inserted Saw Regarding Surface Profiles." 

Content of Wood Samples Using a Pin-Style Moisture Meter

European Journal of Wood and Wood Products (Holz als Roh-und Werkstoff) 63: 256-265.

[7] Okai, R. 2009. "Influence of Vibration Coupling between Bandsaw Frame and Feed-Carriage System on Saw Dust Spillage and Surface Quality of Workpiece during Sawing." European Journal of Wood and Wood Products 67: 189-195.

[8] Okai, R. 2003. "Can Logging Residues be Used to Help Meet the Timber Demands for the Downstream Processing Sector?" In Proceedings of the XII World Forestry Congress, 146-147.

[9] Okai, R. 2002. "A Study of the Milling and Strength Properties of Branchwood Suggests that Logging Residues Could be Used to Help Meet the Timber Demands of the Downstream Processing Centre." ITTO Tropical Forest Update 12 (1): 24-25.

[10] Okai, R., Yokochi, H., and Kimura, S. 1995. "What is the Relationship between Tooth Passage Frequency and the Natural Frequency of the Bandsaw When Self-Excited Vibration and Washboarding are Induced?" In Proceedings of the 12th International Wood Machining
Seminar, 367-380.

[11] Okai, R., Mitchual, S. J., and Frimpong-Mensah, K. 2006 "Optimisation Techniques for Minimizing Saw Teeth Deflection and Lumber Thickness Variation.” Journal of the American Society for Precision Engineering 30: $39-46$.

[12] Okai, R., and Okyere, B. 2006. "Analysis of Sawn Lumber Production from Logging Residues of Branchwood of Aningeria Robusta and Terminalia Ivorensis." European Journal of Forest Research 126: 385-390.

[13] Tanaka, C., and Huang, J. 1995. "On-Line Control of Bandsaw Feed-Speed Using Fuzzy Logic." In Proceedings of the 12th International Wood Machining Seminar, 412-42.

[14] Okai, R., Tanaka, C., and Iwasaki, Y. 2006. "Influence of Mechanical Properties and Mineral Salts in Wood Species on Tool Wear of High-Speed Steels and Stellite-Tipped Tools. Consideration of Tool Wear of the Newly Developed Tip-Inserted Band Saw." European Journal of Wood and Wood Products (Holz als Roh-und Werkstoff) 64: 45-52. 